\title{
Factors influencing the severity of dental caries among Indonesian children with autism spectrum disorder - a pilot study
}

This article was published in the following Dove Press journal:

Clinical, Cosmetic and Investigational Dentistry

\author{
Ninuk Hariyani ${ }^{\prime}$ \\ Roesanto Heroe Soebekti ${ }^{1}$ \\ Dini Setyowati' \\ Taufan Bramantoro' \\ Listyati Setyo Palupi ${ }^{2}$ \\ Oktarina $^{3}$ \\ Ekky Putriana ${ }^{4}$ \\ 'Dental Public Health Department, \\ Faculty of Dental Medicine, Universitas \\ Airlangga, Surabaya, Indonesia; \\ ${ }^{2}$ Personality and Social Psychology \\ Department, Faculty of Psychology, \\ Universitas Airlangga, Surabaya, \\ Indonesia; ${ }^{3}$ Research and Development \\ Centre for Humanities and Health \\ Management, Ministry of Health Republic \\ of Indonesia, Surabaya, Indonesia; \\ ${ }^{4}$ General Dentist, Private Practice, \\ Surabaya, Indonesia
}

Correspondence: Ninuk Hariyani

Dental Public Health Department, Faculty of Dental Medicine, Universitas Airlangga, Surabaya 60132, Indonesia

Tel +62 6I 426255132

Email ninuk.hariyani@adelaide.edu.au

\begin{abstract}
Aim: To assess the prevalence of dental caries among autism spectrum disorders (ASD) children in Surabaya, Indonesia, and to explore the association between oral health-related behaviors comprising toothbrushing, snacking and dental visiting and the severity of caries. Methods: The prevalence and severity of caries were assessed using DMF-T/dmf-t and PUFA/pufa indexes for mixed dentitions. The parents or carers' responses were collected to identify the oral health-related behaviors that were associated with caries severity.

Results: This study shows that almost $79 \%$ of ASD children in Surabaya were experiencing caries and $47.1 \%$ had untreated caries with pulp involvement or more severe conditions. Oral health behaviour factors associated with the severity of dental caries experienced by children with autism were brushing frequency $(\mathrm{B}[95 \% \mathrm{CI}]=2.46[0.09-4.83]$ and $2.03[0.78-3.28])$, brushing time $(\mathrm{B}[95 \% \mathrm{CI}]=3.76[1.32-6.20]$ and $2.03[0.74-3.32])$ and cleansing after snack $(\mathrm{B}[95 \% \mathrm{CI}]=2.04[0.20-3.89]$ and $1.21[0.23-2.18])$ in DMF-T/dmf-t and PUFA/ pufa indexes, respectively.

Conclusions: The prevalence of caries among children with autism in Surabaya was high. The severity was associated with brushing and snacking behaviors. Caries in children with autism should be paid attention, and research in modifying daily activities are needed to allow them to adopt more healthy oral health-related behaviors.
\end{abstract}

Keywords: autism spectrum disorders, caries, oral health related behaviour

\section{Introduction}

Autism spectrum disorders (ASD) are life-long neurodevelopmental disabilities characterized by impairments in reciprocal social interactions, impairments in verbal and nonverbal communication skills and stereotyped behavior, interests and activities. ${ }^{1}$ ASD represent an abnormality of brain development and function, appearing within the first three years of life. Yet, the etiology of autism is unknown but is likely to have multiple etiologies including genetic factors.

The number of children and young people diagnosed with ASD has been growing steadily over the past 10 years. $^{2}$ Acording to estimates from the Center for Disease Control and Prevention's Autism and Developmental Disabilities Monitoring (ADDM) Network, currently about 1 in 68 children in the United States has been identified with ASD. ${ }^{3}$

Dental caries is the common oral manifestation of children with ASD. ${ }^{4}$ Dental caries is a chronic disease that commonly occurs during the lifetime. Untreated dental caries could result in further destructive clinical condition such as pulp 
involvement and abscess ${ }^{5}$ and could impact on the children's quality of life. ${ }^{6,7}$ The occurrence of dental caries in children with ASD can be similar to ${ }^{8,9}$ or even lower ${ }^{10}$ than the general population. However, another study also found a higher prevalence of dental caries in children with ASD than in the general population. ${ }^{11}$ Current systematic review and meta-analysis study verify that the prevalence of dental caries among children and young adults with ASD is $60.6 \% .^{12}$ Even though there are some studies estimating dental caries in ASD children, studies estimating further clinical condition of untreated dental caries among children with ASD are scarce.

In some children with ASD, sweet foods are often given as behavioral rewards. ${ }^{4}$ Consumption of foods with high concentrations of sugar and their prolonged intake play an important role in caries development. ${ }^{13}$ Dental caries occurs as a result of demineralization of enamel and dentine by organic acids. Acids are formed by bacteria in dental plaque through the anaerobic metabolism of dietary sugars. ${ }^{14}$

Dental caries is known as a preventable disease. Epidemiological studies showed a significant role of behavior in caries development. ${ }^{15}$ Poor oral hygiene practice, such as toothbrushing, is one of the key behaviors contributing to caries development in children. ${ }^{16}$ Evidence suggests a proper toothbrushing twice a day is sufficient to maintain oral health. ${ }^{17}$ American Academy of Pediatrics recommended toothbrushing supervision until the age of around 8 years, ${ }^{18}$ whereas the New Zealand Ministry of Health recommended toothbrushing supervision until the age of 6 years. The New Zealand Ministry of Health explained that children aged younger than 6 years still had limited skills for toothbrushing. As a result, without toothbrushing assistance from adults, they were not able to completely remove plaque on their teeth, and thus increased the risk of developing dental caries. ${ }^{19}$

However, proper oral hygiene practices are extremely difficult for many children with ASD. ${ }^{4}$ Children with ASD were known to have a physical impairment that usually prevents them to do self-oral hygiene practices, including toothbrushing. They may require extensive training or assistance from their parents/carer to perform it and to make it as a daily routine habit. For parents/carer, the efforts to help children with ASD adopting proper oral hygiene practices can be stressful with regard to the time and energy required. ${ }^{20}$ Furthermore, restricting children with ASD from sugar consumption may become another challenge for parents/carer as children with ASD have a strong affinity for sweets. ${ }^{21,22}$
Dental visit behaviors have contributed to the treatment of dental caries and could prevent further destruction due to untreated dental caries. However, there are some issues of unmet dental need among children with ASD. ${ }^{23}$ Factors such as child's difficult behavior and difficulties to find a dentist with the skills or willingness to work with people with disabilities influence dental visit behaviors among children with $\mathrm{ASD}^{23}$

Despite the fact of the high risk of dental caries in children with ASD, there is not a great deal of literature on dental caries and oral health behaviors in children with ASD, especially in developing countries. This study aims to assess the prevalence of dental caries and further clinical consequence of untreated dental caries among children with ASD in Surabaya, Indonesia, and to explore the association between oral health behaviors, comprising tooth cleaning strategy, snacking and dental visiting behavior, and dental caries among children with autism.

\section{Materials and methods}

\section{Subjects}

As there is no record on the number of children with ASD, and not all children with ASD in Indonesia get a formal education in an autism rehabilitation center, this study served as a pilot study to assess the aims. Subjects were dyads of children with autism and their parents or carers who were registered from autism rehabilitation centers in Surabaya city, the capital city of East Java Province, Indonesia. Sample selection was done thorough cluster sampling according to autism rehabilitation centers. A quarter of the total number of registered autism rehabilitation centers in Surabaya was included in the study. All autism students from four autism rehabilitation centers chosen randomly were selected as study participants. Among 105 children in the four autism rehabilitation centers, only 70 dyads agreed to participate in this study (response rate for the study is $67 \%$ ). According to the school record of the children's autism category, all the participants were in mild category. Reasons for refusal include do not have time and afraid of the kid's rejection in the oral examination. The study protocol was approved by the Ethics Committee of Faculty of Dental Medicine, Airlangga University. Research was conducted in accordance with the Declaration of Helsinki. Every parent or carer was assured about the confidentiality of data being collected and that the information would only be used for research purpose. Written informed consent was obtained from all parents or carers of children with autism. 


\section{Questionnaire and data collection}

Parents or carers of the children with autism being selected as participants of the study were invited to join the study and give their consent. The children were invited to be examined in the oral examination conducted by one of the researchers (EP). Data collection of the severity of dental caries in children with autism was done in the autism rehabilitation center under sufficient natural light (examination was done near the window in the classroom). This condition was maintained the same in all of the oral examinations. The oral examination was conducted without clinical oral health equipment to prevent the kids' rejection. The kid was made to sit in a chair accompanied by his/her parent/carer while being examined by the oral examiner. The examiner will provide as much as time needed when the kid needs a break and continue the examination afterwards. Data of DMF-T, dmf-t, PUFA and pufa was collected to measure the severity of dental caries. One single coded was written for each tooth present in each measurement. For each measurement, the most severe condition was recorded. DMF-T and dmf-t are well-known measurements recommended by the WHO to measure caries in permanent and deciduous teeth, respectively, recording Decayed (D/d), Missing (M/m) and Filled (F/f) teeth due to caries. ${ }^{24}$ PUFA and pufa are new indexes used for measuring clinical consequences of untreated dental caries in permanent and deciduous teeth, respectively, recording Pulp Involvement $(P / p)$, Ulcer caused by dislocated tooth fragments (U/u), Fistula (F/f) and Abscess (A/a). ${ }^{5}$

A self-administered oral health behavior questionnaire was formulated in a simple Indonesian language and distributed to parents or carers of children with autism. The questionnaire included demographic information (age, gender) and some well-known risk factors for caries related to brushing, snacking and dental visiting behavior. Ten per cent of the participants (dyad of parents-carer and the kid) were asked to complete the self-administered questionnaire and follow another oral examination again to check for test-retest reliability (using Kappa statistics and interclass correlation analysis) after a washout period of 1 month.

\section{Data management}

The severity of caries was reported in two formats using DMF-T/dmf-t index and PUFA/pufa index. In each index, the sum of cases in the deciduous and permanent teeth was reported. Age was dichotomized into $\leq 12$ years old and $\geq 13$ years old. Brushing frequency was recorded either the brushing was done by the kid alone or with the help of the parents/carer. It was coded as twice a day or more vs once a day or less. Brushing time was coded for kids who have a certain brushing time (could be done when having a shower, after breakfast or before bedtime) vs only doing brushing when the kid wants to do it. Time to finish brushing was dichotomized into clean in carer's standard vs when the kid has rejected. Snacking frequency was asking how many times the kids were given between meal snacks per day. It was categorized into less than twice a day and twice a day or more. Parent/carer were also asked about autism kids' immediate activities in relation to the cleaning strategy after eating the snack. In terms of dental visiting behavior, we collected data about reason of dental visit (categorized as checkup vs problems) and the type of treatment chosen by parent/carer to overcome the autism kids' toothache.

\section{Statistical analysis}

The statistical analysis was performed in SAS-callable SUDAAN (Research Triangle Institute, North Carolina). Characteristics of the study participants were presented. Bivariate analysis of the outcome variables and the reported oral health-related behavior were checked using independent $t$-test. Multivariable regression analysis was conducted for each outcome, and the statistical significance of the associations was evaluated at $P<0.05$.

\section{Results}

Seventy dyads (parent-carer and the kid) have a complete data set. High test-retest reliability $(>0.70)$ was noted for all variables in the questionnaire reported by the parentcarer and the results of the oral examination of the kids. Of the autism kids surveyed, more than $60 \%$ were less than 12 years old and almost $75 \%$ were male (Table 1). According to parent/carer's report, around $59 \%$ of children with autism only brushed once a day or less, $37 \%$ only did brushing if the kids wanted it and almost $27 \%$ finished the brushing when the kids refused. Around $51 \%$ of the autism kids had snack between the meal time for more than twice a day and did not do any cleaning strategy such as drink water or brushing after eating the snack. Seventy-three per cent parents reported coming to the dentist only for resolving the kid's oral problems and around 53\% did not bring the kids straight to the dentist for oral health solutions but buy an analgesic or just delay it. 
Table I Characteristics of study participants and the bivariate analysis of the caries experience

\begin{tabular}{|c|c|c|c|c|c|}
\hline \multirow[t]{3}{*}{ Characteristics } & \multirow{3}{*}{$\begin{array}{l}\text { Total } \\
\%\end{array}$} & \multicolumn{4}{|c|}{ Caries in permanent and deciduous teeth } \\
\hline & & \multicolumn{2}{|c|}{ DMF-T + dmf-t } & \multicolumn{2}{|l|}{ PUFA + pufa } \\
\hline & & Mean \pm SD & $P$-value & Mean \pm SD & $P$-value \\
\hline \multicolumn{6}{|l|}{ Age of children with autism } \\
\hline$<13$ years old & 64.3 & $5.20 \pm 4.65$ & $0.02 *$ & $1.52 \pm 2.05$ & 0.61 \\
\hline$\geq 13$ years old & 35.7 & $3.24 \pm 2.20$ & & $1.83 \pm 2.75$ & \\
\hline \multicolumn{6}{|l|}{ Sex of children with autism } \\
\hline Male & 74.3 & $4.44 \pm 3.99$ & 0.841 & $2.09 \pm 2.53$ & $<0.01 *$ \\
\hline Female & 25.7 & $4.67 \pm 4.34$ & & $0.72 \pm 1.17$ & \\
\hline \multicolumn{6}{|l|}{ Brushing frequency } \\
\hline Twice a day or more & 41.4 & $4.03 \pm 4.32$ & 0.42 & $1.07 \pm 1.75$ & 0.09 \\
\hline Once a day or less & 58.6 & $4.83 \pm 3.87$ & & $1.98 \pm 2.47$ & \\
\hline \multicolumn{6}{|l|}{ Brushing time } \\
\hline $\begin{array}{l}\text { At a certain time (when having a shower, after breakfast or before bed } \\
\text { time) }\end{array}$ & 62.9 & $3.82 \pm 3.14$ & 0.11 & $1.32 \pm 1.85$ & 0.17 \\
\hline If the kid wants it & 37.1 & $5.65 \pm 5.11$ & & $2.08 \pm 2.74$ & \\
\hline \multicolumn{6}{|l|}{ Sign of finishing the brushing } \\
\hline Clean in carer's standard & 74.3 & $3.81 \pm 3.86$ & $0.01 *$ & $1.29 \pm 2.24$ & $0.05^{*}$ \\
\hline When the kid has rejected & 25.7 & $6.50 \pm 4.03$ & & $2.50 \pm 2.01$ & \\
\hline \multicolumn{6}{|l|}{ Snacking frequency } \\
\hline Limited (less than twice a day) & 48.6 & $3.35 \pm 3.45$ & $0.02 *$ & $0.79 \pm 1.47$ & $<0.01 *$ \\
\hline Twice a day or more & 51.4 & $5.58 \pm 4.32$ & & $2.36 \pm 2.57$ & \\
\hline \multicolumn{6}{|l|}{ What's done after eat snack } \\
\hline Drink water or brush the teeth & 48.6 & $2.91 \pm 2.93$ & $<0.01 *$ & $0.71 \pm 1.36$ & $<0.01 *$ \\
\hline None & 51.4 & $6.00 \pm 4.4 I$ & & $2.44 \pm 2.57$ & \\
\hline \multicolumn{6}{|l|}{ Reason for dental visit } \\
\hline Checkup & 27.1 & $2.63 \pm 3.45$ & $0.02 *$ & $0.74 \pm 1.79$ & $0.05 *$ \\
\hline Problems & 72.9 & $5.20 \pm 4.06$ & & $1.92 \pm 2.31$ & \\
\hline \multicolumn{6}{|l|}{ Treatment for toothache } \\
\hline Go to dentist & 47.1 & $4.48 \pm 3.70$ & 0.88 & $1.36 \pm 2.25$ & 0.41 \\
\hline None or buy analgetics & 52.9 & $4.43 \pm 4.39$ & & $1.81 \pm 2.23$ & \\
\hline
\end{tabular}

Notes: *Significant, $P$-values generated using independent $t$-test. DMF-T + dmf-t $=$ WHO index to measure caries in permanent and deciduous teeth (Decayed (D/d), Missing $(\mathrm{M} / \mathrm{m})$ and Filled $(\mathrm{F} / \mathrm{f})$ teeth $(\mathrm{T} / \mathrm{t})$ due to caries). PUFA+pufa $=$ new index for measuring clinical consequences of untreated dental caries in permanent and deciduous teeth (Pulp Involvement (P/p), Ulcer caused by dislocated tooth fragments (U/u), Fistula (F/f) and Abscess (A/a)).

The prevalence of caries experience among children with ASD in Surabaya is $78.6 \%$ and $47.1 \%$ measured as DMF-T/dmf-t and PUFA/pufa, respectively. The severity of caries using DMF-T/dmf-t and PUFA/pufa is 4.5 and 1.6 , respectively.

Bivariate analysis is also presented in Table 1. Caries in DMF-T/dmf-t among children with autism aged less than 13 years was significantly higher than their counterpart aged 13 + years (mean $\pm \mathrm{SD}=5.20 \pm 4.65$ vs mean $\pm \mathrm{SD}=3.24 \pm 2.20$ ). Caries in PUFA/pufa, which indicate clinical consequences of untreated root caries, was significantly higher in autism boys compared to autism girls (mean $\pm \mathrm{SD}=2.09 \pm 2.53$ vs mean $\pm \mathrm{SD}=0.72 \pm 1.17)$. In relation to the oral health-related behaviors, children with autism who finished brushing due to kids rejection, had snacking frequency twice a day or more, did nothing after eating snack and only visited a dentist for a problem, have significantly higher caries both measured as DMF-T/dmf-t and PUFA/pufa compared to their counterpart who finished brushing due to carer's clean standard, had limited snacking frequency, had a habit of drinking water or brushing the teeth after eating snack, and visited a dentist for a checkup, respectively.

In the multivariable analysis (Table 2), brushing and snacking behavior were significantly associated with the 
Table 2 Adjusted multivariable analysis between oral health behaviors and dental caries

\begin{tabular}{|c|c|c|c|c|}
\hline \multirow[t]{3}{*}{ Characteristics } & \multicolumn{4}{|c|}{ Caries in permanent and deciduous teeth } \\
\hline & \multicolumn{2}{|l|}{ DMF-T + dmf-t } & \multicolumn{2}{|l|}{ PUFA + pufa } \\
\hline & $\mathrm{B}[95 \% \mathrm{Cl}]$ & $P$-value & $\mathrm{B}[95 \% \mathrm{Cl}]$ & $P$-value \\
\hline Age ( $\geq 13$ years old vs ref. $<13$ years old $)$ & $-1.12[-2.92-0.67]$ & 0.22 & $-0.69[-1.63-0.26]$ & 015 \\
\hline Sex (female vs ref. male) & $-0.62[-2.57-1.32]$ & 0.52 & $-0.09[-1.12-0.93]$ & 0.86 \\
\hline $\begin{array}{l}\text { Brushing frequency (brushed once a day or less vs ref. brushed } \\
\text { twice a day or more) }\end{array}$ & $2.46[0.09-4.83]$ & 0.04 & $2.03[0.78-3.28]$ & $<0.01$ \\
\hline $\begin{array}{l}\text { Brushing time (did not have a certain teeth brushing time during a } \\
\text { day vs ref. have a certain time for teeth brushing) }\end{array}$ & $3.76[1.32-6.20]$ & $<0.01$ & $2.03[0.74-3.32]$ & $<0.01$ \\
\hline $\begin{array}{l}\text { Sign of finishing the brushing (when the kid has rejected vs ref. } \\
\text { clean in carer's standard) }\end{array}$ & $1.07[-0.94-3.09]$ & 0.29 & $0.44[-0.62-1.50]$ & $0.4 \mathrm{I}$ \\
\hline $\begin{array}{l}\text { Snacking frequency (twice a day or more vs ref. limited (less than } \\
\text { twice a day)) }\end{array}$ & $1.51[-0.16-3.18]$ & 0.08 & $1.24[0.36-2.12]$ & $<0.01$ \\
\hline $\begin{array}{l}\text { What's done after eat snack (did nothing after snacking vs ref. } \\
\text { drank water or brushed the teeth soon after snacking) }\end{array}$ & $2.04[0.20-3.89]$ & 0.03 & $1.21[0.23-2.18]$ & 0.02 \\
\hline Reason of dental visit (problems vs ref. check-up) & $1.86[-0.35-4.06]$ & 0.10 & $0.35[-0.8|-| .52]$ & 0.55 \\
\hline $\begin{array}{l}\text { What's done for tooth ache (doing nothing or buy analgetics vs ref. } \\
\text { go to dentist) }\end{array}$ & $-0.89[-2.66-0.88]$ & 0.32 & $0.22[-0.7|-| .16]$ & 0.63 \\
\hline
\end{tabular}

Notes: Multivariable regression analysis; bold = significant; DMF-T + dmf- $\mathrm{t}=\mathrm{WHO}$ index for dental caries in permanent and deciduous teeth; PUFA+pufa $=$ new index for measuring clinical consequences of untreated dental caries in permanent and deciduous teeth.

severity of caries measured as DMF-T/dmf-t and PUFA/pufa. Autism kids who brushed once a day or less had a double chance to have more severe caries than their counterparts who brushed twice a day or more (B $[95 \%$ $\mathrm{CI}]=2.46[0.09-4.83]$ and $\mathrm{B}[95 \% \mathrm{CI}]=2.03[0.78-3.28]$ measured as DMF-T/dmf-t and PUFA/pufa, respectively). Autism kids who did not have a certain teethbrushing time during a day were three times more likely to have more severe caries than those who have a certain time for teethbrushing (regardless whether it was done when having a shower, after breakfast or before the bedtime). Children who did nothing after snacking had a double chance to have more severe caries than their counterparts who drank water or brushed the teeth soon after snacking. Snacking frequency was significantly associated with increased number of teeth experiencing caries with pulp involvement or more severe conditions $(\mathrm{B}[95 \% \mathrm{CI}]=1.24$ [0.36-2.12]).

\section{Discussion}

This study found that caries prevalence among Indonesian children with ASD was $78.6 \%$ with the severity of 4.5 teeth affected by caries. The prevalence of the further clinical consequence of untreated dental caries among Indonesian children with ASD was $47.1 \%$ with the severity of 1.6 teeth. This study also found that the severity of caries both measured as DMF-T/dmf-t and PUFA/pufa among children with autism was associated with brushing and snacking behavior. This study limitation lies in the nature of this cross-sectional study design, which does not allow a causal hypothesis confirmation.

The autism kids who participated in this study were mainly in the mild category of autism; thus, the results could not be generalized for the whole children with autism. Moreover, as the oral examination was conducted without any clinical oral equipment, the results of the caries resemble dentinal cavitated caries. This caries experience could underestimate the real caries experience among children with autism. However, the prevalence of the caries we found here was alarming as the prevalence was high. This study shows that almost $79 \%$ of children with autism in Surabaya experiencing caries and 47.1\% had untreated caries with pulp involvement or more severe conditions. On average, children with autism experienced 4.5 treated and non-treated tooth due to caries and 1.6 pulpally involved tooth in their oral cavity. 
This caries prevalence was higher compared to the prevalence of caries among children with autism reported in the meta-analysis conducted by Da Silva et al in which $60.6 \%$ experience caries. ${ }^{12}$ The prevalence of caries in Indonesian ASD children was also higher than those reported in Hong Kong ASD children in which only 26\% suffered dental caries. ${ }^{25}$ Low prevalence of caries in Hong Kong ASD children was probably influenced by the fact that $70 \%$ of ASD children there had established a twicedaily toothbrushing habit at a mean age of 2.5 years. ${ }^{25}$

Brushing and snacking behavior were found as risk factors for caries among children with autism in Indonesia both measured using DMF-T/dmf-t and PUFA/pufa. One of the factors that influenced the high prevalence of caries in children with autism in this study was their parent/carer. The data showed that most of the parent/carer tended to let their children brushed their teeth according to their child's willingness. The way parents control the frequency of toothbrushing of their children with autism becomes significantly an influence in the level of caries that their children had. Parent/carer who let their children brush their teeth on their own willingness tended to let their children brush only once or even not brushing their teeth at all. On the snacking habit, children with autism who had snacks twice a day or more had more chance to have more severe caries experience than children with autism with a limited snacking frequency. Those conditions while repeated on a daily basis became negative habits that made children's caries even more severe day by day. This finding is congruence with the result of parental attitudes study conducted by Scaglioni et $\mathrm{al}^{26}$ showing that parents' behavior affect their children behavior to develop a healthy eating behavior.

Food is one of the "rewards" most often used to modify behavior. Behavior modification programs for children with behavioral disorders or mental impairments have traditionally used candy, gum, carbonated beverages or sweetened juices for reinforcement because of their low cost and high appeal. ${ }^{27}$ The phenomenon among autistic children is similar to autistic children having a strong affinity for sweets. ${ }^{21,22}$ In this case, as this behavior could impact the health of children with autism in the future, there should be a strong commitment in parent/carer of autism kids to restrict the use of food as a modifying behavior tool for their kids and look for an alternative.

As children with autism usually have difficulties in mobilities, they could also have difficulties in following oral hygiene practices such as tooth brushing individually. At this point, the role of parent/carer is needed. Parent and carer should introduce them to the behavior and set some rules to maintain the behavior such as giving a certain time to brush their teeth, setting a "clean" standard on toothbrushing, setting the rule to drink water soon after snacking or limiting the snacking frequency of the children with autism. Research has shown that autism kids could accept toothbrushing education through visualization and when it was brake in to task analysis. ${ }^{20,28}$ In the task analysis method, children with autism were taught tooth brushing activity by breaking it down into its individual stimulusresponse components. This activity then could be maintained by putting it into the visual schedule until it becomes the children's habit.

Small sample size could be a limitation in this study. However, as there is no data in the exact number of children with ASD in Surabaya, this research could serve as a pilot study on this topic. Future research was needed to confirm the findings. On the other hand, this research was among the few studies which reported the clinical consequences of untreated dental caries in children with ASD. It brings new insight about behavioral factors that influence the severity of dental caries in children with ASD in developing countries, and the findings may be useful for pediatric dentists, especially who work with children with autism from a developing country, in their effort to reduce caries prevalence in children with autism through a specific behavioral intervention program.

\section{Acknowledgments}

The authors thank all the autistic children and the parent(s) who volunteered to participate. The present studies were done with funding from an Indonesian Ministry of Higher Education grant.

\section{Disclosure}

The authors report no conflicts of interest in this work.

\section{References}

1. Centre for developmental disability health, Monash health community. Fact sheet of autism spectrum disorders. Available from: http://www. cddh.monash.org/assets/fs-autism.pdf. [Accessed: January 31, 2017].

2. Delli K, Reichart PA, Bornstein MM, Livas C. Management of children with autism spectrum disorder in the dental setting: concerns, behavioural approaches and recommendations. Med Oral Patol Oral Cir Bucal. 2013;18(6):e862-e868. doi:10.4317/medoral.19084

3. Christensen DL, Baio J, Braun KV, et al. Prevalence and characteristics of autism spectrum disorder among children aged 8 years autism and developmental disabilities monitoring network, 11 sites, United States, 2012. MMWR Surveill Summ. 2016;65(No. SS-3):1-23. doi:10.15585/mmwr.ss6503a1 
4. School of Dentistry, Dental Education in the Care of Persons with Disabilities (DECOD) Program, The University of Washington and Washington State Department of Health Oral Health Program. Oral Health Fact Sheet for Dental Professionals (Children with Autism Spectrum Disorder). Available from: http://dental.washington.edu/ wp-content $/$ media/sp_need_pdfs/Autism-Dental.pdf. [Accessed March 04, 2017].

5. Monse B, Heinrich-weltzien R, Benzian H, Holmgren C, Van Palenstein Helderman W. PUFA - an index of clinical consequences of untreated dental caries. Community Dent Oral Epidemiol. 2010;38 (1):77-82. doi:10.1111/j.1600-0528.2009.00514.x

6. Low W, Tan S, Schwartz S. The effect of severe caries on the quality of life in young children. Pediatr Dent. 1998;21(6):325-326.

7. Filstrup SL, Briskie D, Da Fonseca M, Lawrence L, Wandera A, Inglehart MR. Early childhood caries and quality of life: child and parent perspectives. Pediatr Dent. 2003;25(5):431.

8. El Khatib AA, El Tekeya MM, El Tantawi MA, Omar T. Oral health status and behaviours of children with autism spectrum disorder: a case-control study. Int J Paediatr Dent. 2014;24(4):314-323. doi:10.1111/ipd.12067

9. Bassoukou I, Nicolau J, dos Santos M. Saliva flow rate, buffer capacity, and $\mathrm{pH}$ of autistic individuals. Clin Oral Invest. 2009;13 (1):23-27. doi:10.1007/s00784-008-0209-5

10. Namal N, Vehit HE, Koksal S. Do autistic children have higher levels of caries? A cross-sectional study in Turkish children. J Indian Soc Pedod Prev Dent. 2007;25(2):97-102.

11. Jaber MA. Dental caries experience, oral health status and treatment needs of dental patients with autism. J Appl Oral Sci. 2011;19(3):212. doi:10.1590/S1678-77572011000300006

12. da Silva SN, Gimenez T, Souza RC, et al. Oral health status of children and young adults with autism spectrum disorders: systematic review and meta-analysis. Int J Paediatr Dent. 2017;27(5):388-398.

13. Begzati A, Berisha M, Meqa K. Early childhood caries in preschool children of Kosovo - a serious public health problem. BMC Public Health. 2010;10:788-795. doi:10.1186/1471-2458-10-788

14. Moynihan P. Diet, nutrition and the prevention of dental diseases. Public Health Nutr. 2004;7:201. doi:10.1079/PHN2004662

15. Chu C, Ho P, Lo ECM. Oral health status and behaviours of preschool children in Hong Kong. BMC Public Health. 2012;12(1):767 doi:10.1186/1471-2458-12-767
16. Harris R, Nicoll AD, Adair PM, Pine CM. Risk factors for dental caries in young children: a systematic review of the literature. Community Dent Hlth. 2004;21(1 Suppl):71-85.

17. Blount RL, Santilli L, Stokes TF. Promoting oral hygiene in pediatric dentistry: a critical review. Clin Psychol Rev. 1989;9(6):737-746. doi:10.1016/0272-7358(89)90020-2

18. American Academy of Pediatrics. Maintaining and improving the oral health of young children. Pediatrics. 2014;134(6):1224-1229. doi:10.1542/peds.2014-2984

19. New Zealand Guidelines Group. Guidelines for the use of fluorides. Wellington: Ministry of Health; Available from: http://www.health. govt.nz/system/files/documents/publications/guidelines-for-the-useof-fluoride-nov09.pdf. [Accessed November 03, 2015].

20. Mays NM, Heflin LJ. Increasing independence in self-care tasks for children with autism using self-operated auditory prompts. Res Autism Spect Dis. 2011;5(4):1351-1357. doi:10.1016/j.rasd.2011.01.017

21. Chadha GM, Kakodkar P, Chaugule V, Nimbalkar V. Dental survey of institutionalized children with autistic disorder. Int J Clin Pediatr Dent. 2012;5(1):29-32. doi:10.5005/jp-journals-10005-1130

22. O'Brien G, Whitehouse AM. A psychiatric study of deviant eating behaviour among mentally handicapped adults. Brit J Psychiat. 1990;157:281. doi:10.1192/bjp.157.2.281

23. Brickhouse TH, Farrington FH, Best AM, Ellsworth CW. Barriers to dental care for children in Virginia with autism spectrum disorders. $J$ Dent Child. 2009;76(3):188-193.

24. WHO. Oral Health Surveys. Basic Methods. 4th ed. Geneva: World Health Organization; 2007.

25. Chan DFY, Chan SHY, So HK, et al. Dental health of preschool children with autism spectrum disorder in Hong Kong. Hong Kong $J$ Paediatr. 2014;19(3):161-168.

26. Scaglioni S, Salvioni M, Galimberti C. Influence of parental attitudes in the development of children eating behaviour. Br J Nutr. 2008;99 (S1):S22-S5. doi:10.1017/S0007114508892471

27. Entwistle BA, Casamassimo PS. Assessing dental health problems of children with developmental disabilities. J Dev Behav Pediatr. 1981;2(3):115. doi:10.1097/00004703-198109000-00011

28. Brown R. Training and assessment of toothbrushing skills among children with special needs. In: ProQuest Dissertations and Theses. Stokes TF, Mowery D, Steele H, editors. ProQuest Dissertations Publishing; 2012. doi:10.1094/PDIS-11-11-0999-PDN.
Clinical, Cosmetic and Investigational Dentistry

\section{Publish your work in this journal}

Clinical, Cosmetic and Investigational Dentistry is an international, peer-reviewed, open access, online journal focusing on the latest clinical and experimental research in dentistry with specific emphasis on cosmetic interventions. Innovative developments in dental materials, techniques and devices that improve outcomes and patient satisfaction and preference will be highlighted. The manuscript management system is completely online and includes a very quick and fair peer-review system, which is all easy to use. Visit http://www.dovepress.com/testimonials.php to read real quotes from published authors 